Rollero, C., Daniele, A., \& Tartaglia, S. (2019). Do men post and women view? The role of gender, personality and emotions in online social activity. Cyberpsychology: Journal of Psychosocial Research on Cyberspace, 13(1), article 1. http://dx.doi.org/10.5817/CP2019-1-1

\title{
Do men post and women view? The role of gender, personality and emotions in online social activity
}

\author{
Chiara Rolleroํ, Adriano Daniele ${ }^{2}, \&$ Stefano Tartaglia ${ }^{1}$ \\ ${ }^{1}$ Deparment of Psychology, University of Turin, Torino, Italy \\ ${ }^{2}$ Faculty of Psychology, University Niccolò Cusano, Rome, Italy
}

\begin{abstract}
According to Nadkarni and Hofmann's model (2012), a major motivator of social networking sites (SNS) use is the need to belong, i.e., the basic drive to form and maintain relationships. This need can be fulfilled through two kinds of belongingness-related behaviours: information-seeking (using SNS to learn about others) and communication (using SNS to communicate with others). The present study aimed at examining the role of gender, personality traits and emotional competence on each of these two belongingness-related behaviours. A total of 995 selfselected Italian Internet users (67.1\% women; age range: 18-56) participated in the study. Results showed that the two online behaviours are influenced by different variables. Among them, the most relevant appear to be emotional competences, as managing emotions reduces both behaviours, using emotions fosters communication, and understanding emotions decreases information-seeking. Extraversion plays a key role as well, promoting both behaviours in women and information-seeking in men, whereas openness to experiences is positively linked to viewing others' profiles. Finally, men use social networking sites to communicate and express their opinions more often than women. Implications are discussed.
\end{abstract}

Keywords: Social networking sites; communication; gender; personality; emotional competences

\section{Introduction}

In the recent years social networking sites (SNS) have become part of individuals' daily life and a primary channel for communication and social interaction in the lives of many. Recent estimates indicate there are over 2.23 billion active users on Facebook, 1 billion on Instagram and 335 million on Twitter (Statista, 2018). The fast rise of SNS suggests that they have some attractiveness beyond traditional means of communication. According to Nadkarni and Hofmann's model (2012), a major motivator of SNS use is the need to belong, i.e., the basic drive to form and maintain relationships (Baumeister \& Leary, 1995). This need can be fulfilled through two kinds of belongingnessrelated behaviours: information-seeking (using SNS to learn about others) and communication (using SNS to communicate with others) (Nadkarni \& Hofmann, 2012).

Despite several studies in the field of SNS use, the research regarding the combination of personality and affective factors that influence the specific online behaviours is still at its early stage. The purpose of the present study was to extend past research by examining concurrently the most relevant predictors of SNS use, i.e., gender, personality traits and emotions. Moreover, the effect of such predictors was investigated in relation to each of the two belongingness-related behaviours theorized by Nadkarni and Hofmann (2012), i.e., information-seeking (viewing others' profiles) and communication (actively posting). 


\section{The Use of SNS from a Gender Perspective}

Gender is considered a key variable in understanding SNS use (Brooks \& Longstreet, 2015; Dhir, Pallesen, Torsheim, \& Andreassen, 2016; Haferkamp, Eimler, Papadakis, \& Kruck, 2012; McAndrew \& Jeong, 2012; Pfeil, Arjan, \& Zaphiris, 2009; Tartaglia, 2016). According to Haferkamp and colleagues (2012), men primarily consider SNS as a pragmatic communication medium but not a relevant platform for self-portrayal, whereas women seem to be driven by a more hedonistic motive of self-presentation, which makes them more concerned about how they are perceived by others. Recent research has also found that women use profile pictures for impression management more often than do men (McAndrew \& Jeong, 2012; Sorokowski et al., 2016), in line with stereotypical expectations concerning gender roles (Strano, 2008). When self-disclosure is considered, not all studies have obtained similar findings. Although research about adolescence has shown that females tend to disclose more information online compared to males (Peter, Valkenburg, \& Schouten, 2005), several recent studies concluded that men more easily reveal their personal address and mobile number, maintain less private profiles compared to women, and disclose more personal information (Chang \& Heo, 2014; Special \& Li-Barber, 2012; Taraszow et al., 2010).

In general, literature about the motivations of SNS use has observed that women are more interested in using SNS to maintain existing social relationships, to search for information about others, to pass the time and be entertained (Haferkamp et al., 2012; Hargittai \& Hsieh, 2010; Special \& Li-Barber, 2012; Teppers, Luyckx, Klimstra, \& Goossens, 2014). On the contrary, men tend to use SNS to express their opinions, to develop new relationships, and to experiment with the content they post on their profile (Haferkamp et al., 2012; Wohn \& Lee, 2013). Thus, through SNS men and women seem to gratify different needs. However, to our knowledge, no previous study has considered gender differences in relation to the specific belongingness-related behaviours of information-seeking and communication.

\section{The Influence of Personality on SNS Usage}

The majority of research on the psychological correlates of SNS use and attitudes has focused on personality traits (Hou et al., 2018; Hughes, Rowe, Batey, \& Lee, 2012; Liu \& Campbell, 2017; Oldmeadow, Quinn, \& Kowert, 2013; Pettijohn II, LaPiene, Pettijohn, \& Horting, 2012; Pornsakulvanich, 2017; Ryan \& Xenos, 2011). According to the widely-accepted Five Factor Model of personality (McCrae \& Costa, 1999) individuals vary in terms of extraversion, neuroticism, openness to experiences, agreeableness, and conscientiousness. Extraversion involves sociability, energy, and talkativeness. Neuroticism is characterized by emotional instability and anxiety. Openness is reflected in creativity and preference for novelty. Agreeableness consists of warmth and cooperativeness. Conscientiousness involves discipline and orderliness.

Previous research in the field of SNS has established that three of these traits are central to social media use: extraversion, openness and neuroticism (Correa, Hinsley, \& De Zuniga, 2010; Sorokowska et al., 2016; Zywica \& Danowski, 2008). People who are extraverted are likely to be more frequent users of social media (Blackwell, Leaman, Tramposch, Osborne, \& Liss, 2017; Correa et al., 2010; Liu \& Campbell, 2017; Oldmeadow et al., 2013), have a greater number of online friends (Amichai-Hamburger \& Vinitzky, 2010) and prefer SNS features that allow for active social contribution, such as posting and status updates (Chen, Pan, \& Guo, 2016; Gosling, Augustine, Vazire, Holtzman, \& Gaddis, 2011; Marshall, Lefringhausen, \& Ferenczi, 2015). Similarly, individuals high in open to experiences tend to be drawn to SNS (Correa et al., 2010) and show a greater use of social media especially to find and disseminate information (Hughes et al., 2012). Even elderly people who use SNS show similar patterns, as those with a high level of openness and extraversion have more friends, status updates, and group memberships (Mo, Zhou, Kosinski, \& Stillwell, 2018). Also neuroticism is positively associated with frequency of SNS usage (Blackwell et al., 2017; Correa et al., 2010; Hou et al., 2018). Ross and colleagues (2009) suggest that neurotic people may use SNS to look for the attention and the support that they miss from their everyday lives. Accordingly, a study about Facebook revealed that individuals high in neuroticism use such network for social purposes and engage more frequently than others in emotional disclosure, such as venting about personal problems (Hughes et al., 2012). More recent research has established that individuals with higher neuroticism score use more frequently than others SNSs also to escape from their everyday reality (Orchard, Fullwood, Galbraith, \& Morris, 2014; Wee, Jang, Lee, \& Jang, 2017). However, greater emotional stability seems to be connected with social 
connectedness, i.e., the feelings of belongingness and affiliation that emerge from interpersonal relationships within social networks (Grieve \& Kemp, 2015).

\section{Emotions and Social Media}

Emotional competence, intended as the awareness and expression of affect, emotion identification, situational knowledge, and emotion regulation, is essential for positive social behaviour (Denham et al., 2003; Domitrovich, Cortes, \& Greenberg, 2007; Liu, Li, Carcioppolo, \& North, 2016; Savage, 2002). The theory of emotional intelligence provides a unified framework to study the role of emotional abilities in social functioning (Mayer \& Salovey, 1997; Salovey \& Mayer, 1990). It posits four interrelated central abilities: perceiving, using, understanding, and managing emotions. Perceiving emotions involves the ability to identify emotions in oneself and others. Using emotions pertains to the capacity to take advantage of feelings that assist in specific cognitive tasks, such as problem solving, decision making, and interpersonal communication. Understanding emotions refers to the ability to analyse emotions and the manner in which they combine, evolve and are expressed. Managing emotions involves the capacity to reduce, enhance, or modify an emotional response in oneself and others (Brackett \& Salovey, 2006; Mayer \& Salovey, 1997).

Scholars have suggested that emotional intelligence may influence smartphone behaviour and Internet use (Kun \& Demetrovics, 2010; van Deursen, Bolle, Hegner, \& Kommers, 2015; Wolniewicz, Tiamiyu, Weeks, \& Elhai, 2018). Moving to specific research on SNS, studies have focused on the content of emotions expressed through social media and yielded to inconsistent results. Some authors showed that offline patterns of emotion use are similar to online patterns (Derks, Fischer, \& Bos, 2008), whereas other studies on the messages present in MySpace found that negative emotions are much rare than the positive ones (Thelwall, Wilkinson, \& Uppall, 2010). Reinecke and Trepte (2014) proposed the "positivity bias in SNS communication". According to their research, beneficial forms of authenticity are shown more frequently on SNS and are more likely to receive reinforcement in the SNS context than the negative ones. Consistently, in a study on Facebook by Qiu, Lin, Leung, and Tov (2012), participants revealed a significantly higher willingness to express positive rather than negative emotions and disclosed more positive emotions on Facebook than in their offline interactions.

On the contrary, in their research about the language on social media, Schwartz and colleagues (2013) analysed 700 million words collected from the Facebook messages of 75,000 volunteers and found that people frequently use expressions related to anger and other negative emotions. Moreno et al., (2011) demonstrated that status updates on Facebook could reveal symptoms of major depressive episodes, whereas Oldemeadow and colleagues (2013) showed that individuals with high attachment anxiety used Facebook more frequently, were more likely to use it when feeling negative emotions and were more concerned about others' perception. In line with this idea, there has been growing interest in using social media as a tool for public health, to build insights about depression and other diseases based on postings on social media (De Choudhury, Gamon, Counts, \& Horvitz, 2013; Paul \& Dredze, 2011).

Although all these studies underline the necessity to investigate how individuals manage and express their emotions on SNS, to our knowledge no research has yet considered the relationship between emotional intelligence and the use of social media. Specifically, a lack of knowledge seems to be present about the role of emotional abilities in affecting individuals' behaviours on social networks.

\section{The Current Study}

The purpose of the present study was to extend past research on SNS use. First, we combined research on SNS with the theorisation of Nadkarni and Hofmann (2012) about the need to belong as a major motivator for SNS use. Second, we considered two different behaviours (i.e., information-seeking and actively posting), that, in the perspective of Nadkarni and Hofmann (2012), allow belongingness needs to be met. Third, we examined concurrently the role of gender, personality traits and emotions (past research has tended to consider only one or two of these variables, e.g., Hou et al., 2018; Liu \& Campbell, 2017; Muscanell \& Guadagno, 2012). Fourth, in regards to emotions, we referred to the construct of emotional intelligence (past research has focused on the content of emotions expressed through social media, e.g., Oldmeadow et al., 2013; Qiu et al., 2012; Schwartz et al., 2013). 
Based on the above reported literature, we hypothesized that male gender would associate positively with actively posting (Hypothesis 1), whereas female gender would associate positively with viewing others' profiles (Hypothesis 2) (Haferkamp et al., 2012; Special \& Li-Barber, 2012; Teppers et al., 2014; Wohn \& Lee, 2013). Concerning personality traits, extraversion (Hypothesis 3), openness to experiences (Hypothesis 4), and neuroticism (Hypothesis 5) would associate positively with both actively posting and viewing others' profiles (Blackwell et al., 2017; Chen et al., 2016; Hou et al., 2018; Hughes et al., 2012; Liu \& Campbell, 2017; Wee et al., 2017). Finally, since most literature on emotions seems to suggest a link between SNS usage and a lack of emotional abilities, we hypothesized that emotional intelligence would associate negatively with both actively posting and viewing others' profiles (Hypothesis 6; De Choudhury et al., 2013; Moreno et al., 2011; Oldmeadow et al., 2013; Schwartz et al., 2013).

\section{Method}

\section{Participants}

A total of 995 self-selected Italian Internet users participated in the study. They were recruited through posts on the authors' social networking sites (i.e., Facebook and Twitter). The invitation was posted once a month from July to October 2017. Participants received no compensation. Among them, 13 indicated they do not use any SNS and thus were excluded from analyses. The final sample included 982 participants (67.1\% women). Age ranged from 18 to 56 years $(M=23.88, S D=6.49)$. More than half $(51.7 \%)$ were employed or self-employed and $42.1 \%$ were students.

\section{Materials}

Participants were required to complete an online questionnaire package that comprised measures of personality, emotional intelligence and SNS usage. At the beginning of the questionnaire a plain language explanatory statement informed participants about the aims of the study. They were also informed that participation in the study was voluntary and that their responses were anonymous.

Personality. To assess personality, the Single-Item Measures of Personality (SIMP) (Woods \& Hampson, 2005), a widely used brief measure of the Big-Five dimensions, was included. Research on human personality has shown that personality can be measured reliably and validly with single-items (Bekk, Spörrle, Landes, \& Moser, 2017; Spörrle \& Bekk, 2014). Accordingly, when compared with longer Big Five measures, the SIMP showed good convergent, divergent and criterion correlations, and test-retest reliability was satisfactory (Woods \& Hampson, 2005). In this study, three dimensions were measured: extraversion $(M=5.66, S D=2.34$, skewness $=-0.33$, kurtosis $=-.92)$, neuroticism $(M=3.51, S D=2.28$, skewness $=-0.74$, kurtosis $=-.41)$, and openness to experiences $(M=5.40$, $S D=2.14$, skewness $=-0.25$, kurtosis $=-.74)$. Means scores and standard deviations of extraversion and openness to experiences were in line with those reported in the study by Spörrle and Bekk (2014) (respectively, $M=5.32, S D$ $=2.22$ and $M=5.37, S D=2.08$ ), whereas the mean score of neuroticism was lower than that found in the same research $(M=4.79, S D=2.05)$. Each dimension was assessed with one item made of two opposite descriptions (e.g., "Generally I come across as": "someone who is talkative, outgoing, is comfortable around people, but could be noisy and attention seeking" versus "someone who is reserved, private person, and can be shy around strangers"). A nine-point graded line was placed between the two descriptions and participants were asked to indicate the extent to which one pole or the other best described them.

Emotional intelligence. To assess emotional intelligence, the Schutte Self-Report Emotional Intelligence Test (Schutte et al., 1998) was used. This instrument consists of 33 items rated on a five-point agreement scale (e.g., "I seek out activities that make me happy"). It assesses the four central abilities of emotional intelligence: perceiving emotions ( 10 items, $a=.82, M=3.49, S D=.62$, skewness $=-.24$, kurtosis $=-.22$ ), using emotions ( 6 items, $a=.70$, $M=3.70, S D=.60$ skewness $=-0.33$, kurtosis $=-.06$ ), understanding emotions ( 8 items, $a=.71, M=3.52, S D=.57$, skewness $=-0.43$, kurtosis $=.18$ ), and managing emotions (9 items, $a=.80, M=3.39, S D=.66$, skewness $=-0.27$, kurtosis $=-.00$ ). In line with the conceptualisation of intelligence as a multidimensional ability and with previous studies about this instrument's factorial structure (see Mayer, Caruso, \& Salovey, 2016; Petrides \& Furnham, 2000; Saklofske, Austin, \& Minski, 2003), we used subscales scores. 
SNS usage. Items assessing SNS usage (Bergman, Fearrington, Davenport, \& Bergman, 2011; Correa et al., 2010; Seidman, 2013) were also included. The first item asked participants if they were registered with any online SNSs (e.g., Twitter, Facebook, etc.). Those who were registered with at least one SNS were asked two follow-up questions, (1) "How often do you update your profile or post something?" (7-point scale, ranging from "less than once a week" to "one or more times a hour") $(M=2.47, S D=.86$, skewness $=.91$, kurtosis $=.98)$, and (2) "How often do you view others' profile or read about what your friends are up to?" (7-point scale, ranging from "less than once a week" to "one or more times a hour") $(M=3.73, S D=.87$, skewness $=.01$, kurtosis $=-.52)$.

Demographics. Finally, participants were presented a set of non-identifying demographic questions relating to gender, age, and occupation (i.e., "What is your occupation?". Answers were categorised into "employed or selfemployed"; "student"; "retired"; "other").

\section{Results}

As reported in the previous section, all skewness and kurtosis values were within the range of -1.00 and +1.00 suggested by Muthén and Kaplan (1985), allowing the assumption of normality of data distribution and thus parametric analyses.

Correlations between the studied variables are shown in Table 1.

Table 1. Correlations Between the Studied Variables: Data for Female Sample Above the Midline and Male Sample Below.

\begin{tabular}{|c|c|c|c|c|c|c|c|c|c|c|}
\hline & 1. & 2. & 3. & 4. & 5. & 6. & 7. & 8. & 9. & 10. \\
\hline 1. Age & & $.11 *$ & -.01 & $-.13 * \star$ & $.13^{\star}$ & $.15^{\star \star}$ & $.17 * \star$ & $.17 * \star$ & $-.14 * \star$ & .03 \\
\hline 2. Extraversion & .10 & & -.04 & $-.10 *$ & $.15^{\star \star}$ & $.12^{*}$ & $.36 * \star$ & $.24 * *$ & $.13^{\star \star}$ & $.10 *$ \\
\hline 3. Openness to experiences & -.02 & -.09 & & -.02 & -.02 & $.18^{* *}$ & $.12^{*}$ & .03 & $.10^{*}$ & -.01 \\
\hline 4. Neuroticism & -.04 & -.07 & -.01 & & -.01 & -.03 & .01 & $-.32 * \star$ & -.06 & .04 \\
\hline 5. Perceiving emotions & .10 & $.16^{*}$ & .08 & .01 & & $.38^{* *}$ & $.52 * \star$ & $.41^{\star *}$ & $-.10^{*}$ & .06 \\
\hline 6. Using emotions & .08 & .09 & .09 & .06 & $.36 * \star$ & & $.42 * \star$ & $.50 * *$ & .06 & .08 \\
\hline 7. Understanding emotions & $.15^{\star}$ & $.23 * \star$ & .07 & -.05 & $.57 * \star$ & $.48^{\star \star}$ & & $.48^{* \star}$ & .03 & $.11^{\star}$ \\
\hline 8. Managing emotions & $.11 *$ & $.21 * \star$ & -.02 & $-.42 * \star$ & $.42 * \star$ & $.47 * \star$ & $.50 * \star$ & & $-.12^{\star}$ & .01 \\
\hline 9. Viewing others' profile & -.07 & .04 & .06 & -.07 & $-.07 *$ & .04 & -.06 & $-.17 \star \star$ & & $.27 * \star$ \\
\hline 10. Actively posting & .09 & .08 & -.04 & .08 & .10 & $.19 * *$ & .05 & -.08 & $.27 * \star$ & \\
\hline
\end{tabular}

Note: ${ }^{*} \mathrm{p}<.01 * *_{p}<.001$

Hierarchical regression analyses were then used to test the effect of gender, personality traits and emotional competence on information-seeking (viewing others' profiles) and communication (actively posting). As presented in Table 2, the frequency of viewing others' profiles was not related to gender. Hypotheses about personality traits received partial support, as extraverted and open people were more likely to control others' profiles, whereas neuroticism played no significant role. Finally, the dimensions of emotional intelligence proved to have significant effects, as individuals low in perceiving, managing and understanding emotions more frequently viewed others' profiles.

Results about the frequency of actively posting are presented in Table 3. Men reported posting more frequently than women. Among personality traits, extraversion was positively related to this behaviour, whereas the others traits played no significant role. Concerning emotional intelligence, there was a positive connection between the ability of using emotions and the frequency of posting, as well as a negative relationship between the competence of managing emotions and such frequency. 
Table 2. Multiple Regression Analysis Predicting the Frequency of Viewing Others' Profiles.

\begin{tabular}{lcccc}
\hline Predictor & $\boldsymbol{B}$ & $\boldsymbol{S E}$ & $\boldsymbol{\beta}$ & $\boldsymbol{t}$ \\
\hline Sex (1 = female) & .08 & .06 & .04 & 1.21 \\
Age & -.02 & .00 & $-.11 * *$ & -3.25 \\
Extraversion & .05 & .01 & $.12 * * *$ & 3.63 \\
Openness to experiences & .04 & .01 & $.10 * *$ & -3.12 \\
Neuroticism & -.00 & .01 & -.01 & -0.22 \\
Perceiving emotions & -.12 & .05 & $-.09 *$ & -2.30 \\
Using emotions & .06 & .05 & .04 & 1.12 \\
Understanding emotions & -.16 & .06 & $-.10 *$ & 2.46 \\
Managing emotions & -.24 & .06 & $-.18 * * *$ & -4.22 \\
\hline
\end{tabular}

Note: $R^{2}$ Adj. $=.26, F(9,981)=25.64 * \star \star$

${ }^{*} p<.05 * * p<.01 * * \star p<.001$

Table 3. Multiple Regression Analysis Predicting the Frequency of Posting.

\begin{tabular}{lcccc}
\hline Predictor & $\boldsymbol{B}$ & SE & $\boldsymbol{\beta}$ & $\boldsymbol{t}$ \\
\hline Sex (1 = female) & -.22 & .06 & $-.11 * \star$ & -3.73 \\
Age & .01 & .00 & .04 & 1.14 \\
Extraversion & .03 & .01 & $.08 *$ & 2.17 \\
Openness to experiences & -.01 & .01 & -.04 & -1.12 \\
Neuroticism & .01 & .01 & .03 & 0.71 \\
Perceiving emotions & .05 & .05 & .04 & 0.95 \\
Using emotions & .17 & .06 & $.12 * *$ & 3.12 \\
Understanding emotions & .05 & .06 & .03 & 0.77 \\
Managing emotions & -.12 & .06 & $-.09 *$ & -2.11 \\
\hline
\end{tabular}

Note: $R^{2}$ Adj. $=.20, F(9,979)=16.61^{* \star *}$

${ }^{*} p<.05 * \star p<.01 * * \star p<.001$

Since gender played a significant role on actively posting, we performed separate regression analyses for men and women. As presented in Table 4, in both genders the frequency of posting was positively related to using emotions and negatively linked to managing emotions. However, extraversion proved to have a significant positive effect only in the female sample.

\section{Discussion}

Literature on social media has largely analysed how people use SNS to satisfy their needs (see, for instance, the uses-and-gratifications approach, Katz, Blumler, \& Gurevitch, 1974; Leiner, Kobilke, Rueß, \& Brosius, 2018). In the theorisation of Nadkarni and Hofmann (2012), people use SNS to fulfil the basic need to form and maintain social relationships. This need is satisfied through two specific behaviours: information-seeking and communication. The present study aimed at examining the role of gender, personality traits and emotional competence on each of these belongingness-related behaviours.

Consistent with our prediction (Hypothesis 1), men use SNS to post more often than women. This datum seems to be in line with literature showing that men consider SNS basically as a pragmatic communication medium (Chang \& Heo, 2014; Haferkamp et al., 2012; Special \& Li-Barber, 2012). The same result may also suggest the presence of gender stereotypes, as set of beliefs concerning attributes that are supposed to differentiate women and men (Ashmore \& Del Boca, 1981). According to the most relevant approaches to the conceptualisation of gender stereotypes (Eagly, 2005; Williams \& Best, 1990), men are supposed to show characteristics describing primarily as agentic, assertive and active, whereas women are expected be communal, kind and passive. Thus, social norms seem not completely reinvented online; rather, offline gender stereotypes and roles guide 


\begin{tabular}{|c|c|c|c|c|}
\hline Predictor & $B$ & SE & $\beta$ & $t$ \\
\hline \multicolumn{5}{|c|}{ MEN $R^{2}$ Adj. $=.07, F(8,322)=6.15^{\star \star}$} \\
\hline Age & .01 & .01 & .05 & 0.96 \\
\hline Extraversion & .03 & .01 & .06 & 1.09 \\
\hline Openness to experiences & -.02 & .02 & -.05 & -0.96 \\
\hline Neuroticism & .03 & .01 & .06 & 1.02 \\
\hline Perceiving emotions & .05 & .05 & .04 & 0.94 \\
\hline Using emotions & .37 & .11 & $.24 * *$ & 3.33 \\
\hline Understanding emotions & -.05 & .04 & .04 & 0.93 \\
\hline Managing emotions & -.11 & .06 & $-.09 *$ & -2.08 \\
\hline \multicolumn{5}{|c|}{ WOMEN $R^{2}$ Adj. $=.14, F(8,655)=11.95 * *$} \\
\hline Age & .00 & .01 & .05 & 0.98 \\
\hline Extraversion & .08 & .06 & $.10 *$ & 2.25 \\
\hline Openness to experiences & -.02 & .03 & -.04 & -0.97 \\
\hline Neuroticism & .01 & .01 & .03 & 0.72 \\
\hline Perceiving emotions & .06 & .04 & .05 & 0.96 \\
\hline Using emotions & .11 & .06 & $.10 *$ & 2.11 \\
\hline Understanding emotions & .08 & .05 & .08 & 1.94 \\
\hline Managing emotions & -.13 & .05 & $-.10^{*}$ & -2.13 \\
\hline
\end{tabular}

Note: ${ }^{*} p<.05 * * p<.01 * * * p<.001$

expectations for appropriate behaviour online (Manago, Graham, Greenfield, \& Salimkhan, 2008). However, contrary to our Hypothesis 2, the frequency of viewing others' profiles seems not related to gender. This may be due to the specific features of online communication and to the way gender roles emerge online (see March, Grieve, Marx, \& Witteveen, 2013). Indeed, although literature describes women as more relationship oriented and more interested in maintaining social links (Eagly, 2005; Rollero, 2016), relationships in SNS have different characteristics than those offline (Cummings, Butler, \& Kraut, 2002). According to March and colleagues (2013), online communication can decrease individuals' social desirability even in reference to gender role orientation, as the online environment seems to create an interpersonal social situation in which people feel less concerned about they appear to others. For this reason, the authors suggest to exert caution when assuming construct equivalence of online and offline assessments. Another issue to be considered is that SNS support both the maintenance of existing social ties and the formation of new links and in the current study this aspect was not controlled. Theoretically, there might be a difference between viewing others' profile for searching information about close friends or about superficially known people.

Concerning the role of personality traits, as expected (Hypothesis 3) extraversion positively related to both information-seeking and communication. Extraverted, rather than introverted individuals, tend to engage more frequently in social media use (Correa et al., 2010; Liu \& Campbell, 2017; Mo et al., 2018, Oldmeadow et al., 2013) and appreciate an active social contribution, such as posting and status updates (Chen et al., 2016; Gosling et al., 2011; Marshall et al., 2015). Nevertheless, when findings about posting were considered separately for men and women, extraversion played a significant role only among women. This may be in line with the above described conceptualisation of gender stereotypes that describe women as more passive than men (Eagly, 2005; Williams \& Best, 1990). In this case, extraversion seems to act as a buffer against gender stereotypes, leading women to be more active and agentic.

Hypothesis 4 was only partially supported, as openness to experiences resulted instead related only to viewing others' profiles. The presence of this relation may be due to the curiosity about others of people high in openness. Surprisingly, neuroticism played no significant role on SNS use, contrary to Hypothesis 5 and previous literature suggesting that neurotic people use SNS to look for the attention and the support that they miss from their everyday lives (Hughes et al., 2012; Orchard et al., 2014; Ross et al., 2009, Wee et al., 2017). However, our results are consistent with those obtained by Muscanell and Guadagno (2012) who found that neuroticism was unrelated 
to SNS use. As they suggest, this can be a consequence of the characteristics of the sample: in their study, as well as in ours, the sample consisted in individuals who were particularly low in neuroticism.

About emotional intelligence, as expected (Hypothesis 6) the relationship between managing emotions and online behaviours was negative. In line with studies on emotions and social media (De Choudhury et al., 2013; Paul \& Dredze, 2011), we can suppose that individuals less able in managing their emotional response are those who more frequently could drive their attention to virtual environments, such as SNS, both to distract themselves and to unload and vent. Accordingly, people scoring lower on perceiving and understanding emotions more frequently engaged in viewing others' profiles. In other words, an increased attention to others is significantly linked to a scarce self-reported ability to identify and analyse emotions in oneself. Another potential interpretation may be based on the effect of SNS exposure on emotion regulation. Indeed, recent literature on emotional competence has suggested a negative link between skills in regulating emotions and the use of digital media, as the Internet can act as a dysfunctional regulator of emotional distress (Gámez-Guadix, 2014; Hoge, Bickham, \& Cantor, 2017). Instead, using emotions seems to be positively related to communication, as individuals able to take advantage of their feelings engage in active posting more frequently, probably because this competence is connected with selfconfidence in interpersonal communication (Brackett \& Salovey, 2006).

\section{Limitations and Future Research}

To our knowledge, this is the first study examining concurrently gender, personality traits and emotional competence on SNS use and this might explain the partial discrepancy with previous literature. For instance, the absence of a significant link between openness to experiences and posting is not surprising, as this trait refers to the preference for novelty but not to talkativeness. However, more research is needed to confirm and strengthen these results. A recent study has suggested to examine the combined/interactive effect of personality trait in predicting SNS use, as the level of one trait may strengthen or weaken the relationship between another trait and criterion variables (La Sala, Skues, \& Grant, 2014).

Developing a richer measure of social media use is also a necessary avenue for future studies. Indeed, one important limitation is that we measured SNS use with questions covering a broad range of SNS and SNS behaviours. Moreover, our research was based on participants' self-reported behaviour. More accurate and objective estimates can be acquired, for instance, by coding participants' actual posting and recording the number of comments received to each topic. Similarly, emotional competence was assessed through participants' selfperceptions. Future research should consider also other measuring instruments, such as those based on performance (Megías, Gómez-Leal, Gutiérrez-Cobo, Cabello, \& Fernández-Berrocal, 2018).

Another limitation pertains to the consideration of only one specific cultural context. Considering the high prevalence of studies from the U.S., this research extends the population considered until now. However, even in this case the context was an individualistic Western country and literature argues that people from individualistic cultures use SNS in a very different way compared to users from collectivistic cultures (Lewis \& George, 2008). Further research is needed to compare different cultural contexts.

Since our results demonstrated that gender influences SNS use and the predictors of such use may differ according to gender, future studies should take into account the role of other individual variables as a function of gender. Indeed, predictors affecting online behaviours may play a different role in men and women. Specific assessments and analyses (such as moderation analyses, see Gattino, Rollero, \& De Piccoli, 2015; Rollero, Fedi, \& De Piccoli, 2016) should be considered to this aim.

Finally, since this was the first attempt to investigate predictors of the above described behaviours, relevant variables have been omitted, such as social exhibitionism, narcissism, shyness and loneliness. All these characteristics are significantly related to online social interactions (Baker \& Oswald, 2010; Ryan \& Xenos, 2011) and might be included in future research. 


\section{Conclusion}

Taken together, the present findings reveal that the two specific online behaviours, i.e., information-seeking and communication, are related to different variables. Extraversion plays a key role, positively relating to both behaviours for women and to information-seeking for men, whereas openness to experiences is positively linked to viewing others' profiles. However, the most relevant variables appear to be self-perceived emotional competences. Specifically, self-reported ability in managing emotions is negatively connected to both behaviours, self-reported ability in using emotions is positively related to communication, and self-reported ability in understanding emotions negatively relate to information-seeking.

In terms of practical implications, these results may be useful in developing educational and preventive programs to foster a reflexive attitude on the link between emotions and SNS use. For instance, media literacy programs should not only take into account how emotional intelligence can influence online behaviour but also how promote such intelligence. Indeed, the present findings suggest that it is necessary to broaden the conception of social media literacy as improvement of technical and cognitive skills (Hancock, Keast, \& Ellis, 2017), including also emotion-regulation competences.

\section{References}

Amichai-Hamburger, Y., \& Vinitzky, G. (2010). Social network use and personality. Computers in Human Behavior, 26, 1289-1295. https://doi.org/10.1016/j.chb.2010.03.018

Ashmore, R. D., \& Del Boca, F. K. (1981). Conceptual approaches to stereotypes and stereotyping. In D. L. Hamilton (Ed.), Cognitive processes in stereotyping and intergroup behaviour (pp. 1-35). Hillsdale, NJ: Erlbaum.

Baker, L. R., \& Oswald, D. L. (2010). Shyness and online social networking services. Journal of Social and Personal Relationships, 27, 873-889. https://doi.org/10.1177/0265407510375261

Baumeister, R. F., \& Leary, M. R. (1995). The need to belong: Desire for interpersonal attachments as a fundamental human motivation. Psychological Bulletin, 117, 497-529. https://doi.org/10.1037/0033-

2909.117.3.497

Bekk, M., Spörrle, M., Landes, M., \& Moser, K. (2017). Traits grow important with increasing age: Customer age, brand personality and loyalty. Journal of Business Economics, 87, 511-531. https://doi.org/10.1007/s11573-0160834-4

Bergman, S. M., Fearrington, M. E., Davenport, S. W., \& Bergman, J. Z. (2011). Millennials, narcissism, and social networking: What narcissists do on social networking sites and why. Personality and Individual Differences, 50, 706-711. https://doi.org/10.1016/j.paid.2010.12.022

Blackwell, D., Leaman, C., Tramposch, R., Osborne, C., \& Liss, M. (2017). Extraversion, neuroticism, attachment style and fear of missing out as predictors of social media use and addiction. Personality and Individual

Differences, 116, 69-72. https://doi.org/10.1016/j.paid.2017.04.039

Brackett, M. A., \& Salovey, P. (2006). Measuring emotional intelligence with the Mayer-Salovery-Caruso Emotional Intelligence Test (MSCEIT). Psicothema, 18(Suppl.), 34-41. Retrieved from

http://www.psicothema.com/english/psicothema.asp?id=3273

Brooks, S., \& Longstreet, P. (2015). Social networking's peril: Cognitive absorption, social networking usage, and depression. Cyberpsychology: Journal of Psychosocial Research on Cyberspace, 9(4), article 5.

http://dx.doi.org/10.5817/CP2015-4-5

Chang, C. W., \& Heo, J. (2014). Visiting theories that predict college students' self-disclosure on

Facebook. Computers in Human Behavior, 30, 79-86. https://doi.org/10.1016/j.chb.2013.07.059 
Chen, X., Pan, Y., \& Guo, B. (2016). The influence of personality traits and social networks on the self-disclosure behavior of social network site users. Internet Research, 26, 566-586. https://doi.org/10.1108/IntR-05-2014-0145

Correa, T., Hinsley, A. W., \& De Zuniga, H. G. (2010). Who interacts on the Web?: The intersection of users' personality and social media use. Computers in Human Behavior, 26, 247-253.

https://doi.org/10.1016/j.chb.2009.09.003

Cummings, J. N., Butler, B., \& Kraut, R. (2002). The quality of online social relationships. Communications of the ACM, 45(7), 103-108. https://doi.org/10.1145/514236.514242

De Choudhury, M., Gamon, M., Counts, S., \& Horvitz, E. (2013). Predicting depression via social media. In Proceedings of the Seventh International AAAI Conference on Weblogs and Social Media (pp. 128-137). Retrieved from https://www.aaai.org/ocs/index.php/ICWSM/ICWSM13/paper/view/6124/6351

Denham, S. A., Blair, K. A., DeMulder, E., Levitas, J., Sawyer, K., Auerbach-Major, S., \& Queenan, P. (2003). Preschool emotional competence: Pathway to social competence?. Child Development, 74, 238-256. https://doi.org/10.1111/1467-8624.00533

Derks, D., Fischer, A. H., \& Bos, A. E. (2008). The role of emotion in computer-mediated communication: A review. Computers in Human Behavior, 24, 766-785. https://doi.org/10.1016/j.chb.2007.04.004

Dhir, A., Pallesen, S., Torsheim, T., \& Andreassen, C. S. (2016). Do age and gender differences exist in selfierelated behaviours?. Computers in Human Behavior, 63, 549-555. https://doi.org/10.1016/j.chb.2016.05.053

Domitrovich, C. E., Cortes, R. C., \& Greenberg, M. T. (2007). Improving young children's social and emotional competence: A randomized trial of the preschool "PATHS" curriculum. The Journal of Primary Prevention, 28, 6791. https://doi.org/10.1007/s10935-007-0081-0

Eagly, A. H. (2005). Achieving relational authenticity in leadership: Does gender matter?. The Leadership Quarterly, 16, 459-474. https://doi.org/10.1016/j.leaqua.2005.03.007

Gattino, S., Rollero, C., \& De Piccoli, N. (2015). The influence of coping strategies on quality of life from a gender perspective. Applied Research in Quality of Life, 10, 689-701. https://doi.org/10.1007/s11482-014-9348-9

Gámez-Guadix, M. (2014). Depressive symptoms and problematic Internet use among adolescents: Analysis of the longitudinal relationships from the cognitive-behavioral model. Cyberpsychology, Behavior, and Social Networking, 17, 714-719. https://doi.org/10.1089/cyber.2014.0226

Grieve, R., \& Kemp, N. (2015). Individual differences predicting social connectedness derived from Facebook: Some unexpected findings. Computers in Human Behavior, 51, 239-243. https://doi.org/10.1016/j.chb.2015.04.034

Gosling, S. D., Augustine, A. A., Vazire, S., Holtzman, N., \& Gaddis, S. (2011). Manifestations of personality in online social networks: Self-reported Facebook-related behaviors and observable profile information. Cyberpsychology, Behavior, and Social Networking, 14, 483-488. https://doi.org/10.1089/cyber.2010.0087

Haferkamp, N., Eimler, S. C., Papadakis, A. M., \& Kruck, J. V. (2012). Men are from Mars, women are from Venus? Examining gender differences in self-presentation on social networking sites. Cyberpsychology, Behavior, and Social Networking, 15, 91-98. https://doi.org/10.1089/cyber.2011.0151

Hancock, K., Keast, H., \& Ellis, W. (2017). The impact of cyber dating abuse on self-esteem: The mediating role of emotional distress. Cyberpsychology: Journal of Psychosocial Research on Cyberspace, 11(2), article 2. http://dx.doi.org/10.5817/CP2017-2-2

Hargittai, E., \& Hsieh, Y. L. P. (2010). Predictors and consequences of differentiated practices on social network sites. Information, Communication \& Society, 13, 515-536. https://doi.org/10.1080/13691181003639866 
Hoge, E., Bickham, D., \& Cantor, J. (2017). Digital media, anxiety, and depression in children. Pediatrics, 140(Suppl. 2), S76-S80. https://doi.org/10.1542/peds.2016-1758G

Hou, J., Ndasauka, Y., Jiang, Y., Chen, S., Xu, F., \& Zhang, X. (2018). Weibo or WeChat? Assessing preference for social networking sites and role of personality traits and psychological factors. Frontiers in Psychology, 9. https://doi.org/10.3389/fpsyg.2018.00545

Hughes, D. J., Rowe, M., Batey, M., \& Lee, A. (2012). A tale of two sites: Twitter vs. Facebook and the personality predictors of social media usage. Computers in Human Behavior, 28, 561-569.

https://doi.org/10.1016/j.chb.2011.11.001

Katz, E., Blumler, J. G., \& Gurevitch, M. (1974). Utilization of Mass Communication by the Individual. In J. G. Blumler, \& E. Katz (Eds.), The Uses of Mass Communications: Current Perspectives on Gratifications Research (pp. 1931). Beverly Hills: Sage Publications.

Kun, B., \& Demetrovics, Z. (2010). Emotional intelligence and addictions: a systematic review. Substance Use \& Misuse, 45, 1131-1160. https://doi.org/10.3109/10826080903567855

La Sala, L., Skues, J., \& Grant, S. (2014). Personality traits and Facebook use: The combined/interactive effect of extraversion, neuroticism and conscientiousness. Social Networking, 3, 211-219.

https://doi.org/10.4236/sn.2014.35026

Leiner, D. J., Kobilke, L., Rueß, C., \& Brosius, H. B. (2018). Functional domains of social media platforms: Structuring the uses of Facebook to better understand its gratifications. Computers in Human Behavior, 83, 194203. https://doi.org/10.1016/j.chb.2018.01.042

Lewis, C. C., \& George, J. F. (2008). Cross-cultural deception in social networking sites and face-to-face communication. Computers in Human Behavior, 24, 2945-2964. https://doi.org/10.1016/j.chb.2008.05.002

Liu, D., \& Campbell, W. K. (2017). The Big Five personality traits, Big Two metatraits and social media: A metaanalysis. Journal of Research in Personality, 70, 229-240. https://doi.org/10.1016/j.jrp.2017.08.004

Liu, J., Li, C., Carcioppolo, N., \& North, M. (2016). Do our Facebook friends make us feel worse? A study of social comparison and emotion. Human Communication Research, 42, 619-640. https://doi.org/10.1111/hcre.12090

Manago, A. M., Graham, M. B., Greenfield, P. M., \& Salimkhan, G. (2008). Self-presentation and gender on MySpace. Journal of Applied Developmental Psychology, 29, 446-458. https://doi.org/10.1016/j.appdev.2008.07.001

March, E., Grieve, R., Marx, E., \& Witteveen, K. (2013). More of a (wo) man offline? Gender roles measured in online and offline environments. Personality and Individual Differences, 55, 887-891.

https://doi.org/10.1016/j.paid.2013.07.018

Marshall, T. C., Lefringhausen, K., \& Ferenczi, N. (2015). The Big Five, self-esteem, and narcissism as predictors of the topics people write about in Facebook status updates. Personality and Individual Differences, 85, 35-40. https://doi.org/10.1016/j.paid.2015.04.039

Mayer, J. D., Caruso, D. R., \& Salovey, P. (2016). The ability model of emotional intelligence: Principles and updates. Emotion Review, 8, 290-300. https://doi.org/10.1177/1754073916639667

Mayer, J. D., \& Salovey, P. (1997). What is emotional intelligence? In P. Salovey \& D. Sluyter (Eds.), Emotional development and emotional intelligence: Educational implications (pp. 3-31). New York, NY: Basic Books.

McAndrew, F. T., \& Jeong, H. S. (2012). Who does what on Facebook? Age, sex, and relationship status as predictors of Facebook use. Computers in Human Behavior, 28, 2359-2365.

https://doi.org/10.1016/j.chb.2012.07.007 
McCrae, R. R., \& Costa Jr., P. T. (1999). A five-factor theory of personality. In L. A. Pervin \& O. P. John (Eds.), Handbook of personality psychology (pp. 139-153). New York, NY: Guilford.

Megías, A., Gómez-Leal, R., Gutiérrez-Cobo, M. J., Cabello, R., \& Fernández-Berrocal, P. (2018). The relationship between aggression and ability emotional intelligence: The role of negative affect. Psychiatry Research, 270, 10741081. https://doi.org/10.1016/j.psychres.2018.05.027

Mo, F., Zhou, J., Kosinski, M., \& Stillwell, D. (2018). Usage patterns and social circles on Facebook among elderly people with diverse personality traits. Educational Gerontology, 44, 265-275.

https://doi.org/10.1080/03601277.2018.1459088

Moreno, M. A., Jelenchick, L. A., Egan, K. G., Cox, E., Young, H., Gannon, K. E., \& Becker, T. (2011). Feeling bad on Facebook: depression disclosures by college students on a social networking site. Depression and Anxiety, 28, 447455. https://doi.org/10.1002/da.20805

Muscanell, N. L., \& Guadagno, R. E. (2012). Make new friends or keep the old: Gender and personality differences in social networking use. Computers in Human Behavior, 28, 107-112. https://doi.org/10.1016/j.chb.2011.08.016

Muthén, B., \& Kaplan, D. (1985). A comparison of some methodologies for the factor analysis of non-normal Likert variables. British Journal of Mathematical and Statistical Psychology, 38, 171-189.

https://doi.org/10.1111/j.2044-8317.1985.tb00832.x

Nadkarni, A., \& Hofmann, S. G. (2012). Why do people use Facebook?. Personality and individual differences, 52, 243-249. https://doi.org/10.1016/j.paid.2011.11.007

Oldmeadow, J. A., Quinn, S., \& Kowert, R. (2013). Attachment style, social skills, and Facebook use amongst adults. Computers in Human Behavior, 29, 1142-1149. https://doi.org/10.1016/j.chb.2012.10.006

Orchard, L. J., Fullwood, C., Galbraith, N., \& Morris, N. (2014). Individual differences as predictors of social networking. Journal of Computer-Mediated Communication, 19, 388-402. https://doi.org/10.1111/jcc4.12068

Paul, M. J., \& Dredze, M. (2011). You are what you Tweet: Analyzing Twitter for public health. In Proceedings of the Fifth International AAAI Conference on Weblogs and Social Media (pp. 265-272). Retrieved from https://www.aaai.org/ocs/index.php/ICWSM/ICWSM11/paper/view/2880/3264

Peter, J., Valkenburg, P. M., \& Schouten, A. P. (2005). Developing a model of adolescent friendship formation on the Internet. CyberPsychology \& Behavior, 8, 423-430. https://doi.org/10.1089/cpb.2005.8.423

Petrides, K. V., \& Furnham, A. (2000). On the dimensional structure of emotional intelligence. Personality and Individual Differences, 29, 313-320. https://doi.org/10.1016/S0191-8869(99)00195-6

Pettijohn II, T., LaPiene, K., Pettijohn, T., \& Horting, A. (2012). Relationships between Facebook intensity, friendship contingent self-esteem, and personality in U.S. college students. Cyberpsychology: Journal of Psychosocial Research on Cyberspace, 6(1), article 2. http://dx.doi.org/10.5817/CP2012-1-2

Pornsakulvanich, V. (2017). Personality, attitudes, social influences, and social networking site usage predicting online social support. Computers in Human Behavior, 76, 255-262. https://doi.org/10.1016/j.chb.2017.07.021

Pfeil, U., Arjan, R., \& Zaphiris, P. (2009). Age differences in online social networking-A study of user profiles and the social capital divide among teenagers and older users in MySpace. Computers in Human Behavior, 25, 643654. https://doi.org/10.1016/j.chb.2008.08.015

Qiu, L., Lin, H., Leung, A. K., \& Tov, W. (2012). Putting their best foot forward: Emotional disclosure on Facebook. Cyberpsychology, Behavior, and Social Networking, 15, 569-572. https://doi.org/10.1089/cyber.2012.0200 
Reinecke, L., \& Trepte, S. (2014). Authenticity and well-being on social network sites: A two-wave longitudinal study on the effects of online authenticity and the positivity bias in SNS communication. Computers in Human Behavior, 30, 95-102. https://doi.org/10.1016/j.chb.2013.07.030

Rollero, C. (2016). The experience of men caring for a partner with multiple sclerosis. Journal of Nursing Scholarship, 48, 482-489. https://doi.org/10.1111/jnu.12231

Rollero, C., Fedi, A., \& De Piccoli, N. (2016). Gender or occupational status: What counts more for well-being at work?. Social Indicators Research, 128, 467-480. https://doi.org/10.1007/s11205-015-1039-x

Ross, C., Orr, E. S., Sisic, M., Arseneault, J. M., Simmering, M. G., \& Orr, R. R. (2009). Personality and motivations associated with Facebook use. Computers in Human Behavior, 25, 578-586.

https://doi.org/10.1016/j.chb.2008.12.024

Ryan, T., \& Xenos, S. (2011). Who uses Facebook? An investigation into the relationship between the Big Five, shyness, narcissism, loneliness, and Facebook usage. Computers in Human Behavior, 27, 1658-1664. https://doi.org/10.1016/j.chb.2011.02.004

Saklofske, D. H., Austin, E. J., \& Minski, P. S. (2003). Factor structure and validity of a trait emotional intelligence measure. Personality and Individual Differences, 34, 707-721. https://doi.org/10.1016/S0191-8869(02)00056-9

Salovey, P. \& Mayer, J. D. (1990). Emotional intelligence. Imagination, Cognition and Personality, 9, 185-211. https://doi.org/10.2190/DUGG-P24E-52WK-6CDG

Savage, C. R. (2002). The role of emotion in strategic behavior: Insights from psychopathology. In L. F. Barrett \& P. Salovey (Eds). The wisdom in feeling: Psychological processes in emotional intelligence (pp. 211-236). New York, NY, US: Guilford Press.

Schutte, N. S., Malouff, J. M., Hall, L. E., Haggerty, D. J., Cooper, J. T., Golden, C. J., \& Dornheim, L. (1998). Development and validation of a measure of emotional intelligence. Personality and Individual Differences, 25, 167-177. https://doi.org/10.1016/S0191-8869(98)00001-4

Schwartz, H. A., Eichstaedt, J. C., Kern, M. L., Dziurzynski, L., Ramones, S. M., Agrawal, M., ...Ungar, L. H. (2013). Personality, gender, and age in the language of social media: The open-vocabulary approach. PLoS One, 8(9), e73791. https://doi.org/10.1371/journal.pone.0073791

Seidman, G. (2013). Self-presentation and belonging on Facebook: How personality influences social media use and motivations. Personality and Individual Differences, 54, 402-407. https://doi.org/10.1016/j.paid.2012.10.009

Sorokowska, A., Oleszkiewicz, A., Frackowiak, T., Pisanski, K., Chmiel, A., \& Sorokowski, P. (2016). Selfies and personality: Who posts self-portrait photographs?. Personality and Individual Differences, 90, 119-123. https://doi.org/10.1016/j.paid.2015.10.037

Sorokowski, P., Sorokowska, A., Frackowiak, T., Karwowski, M., Rusicka, I., \& Oleszkiewicz, A. (2016). Sex differences in online selfie posting behaviors predict histrionic personality scores among men but not women. Computers in Human Behavior, 59, 368-373. https://doi.org/10.1016/j.chb.2016.02.033

Special, W. P., \& Li-Barber, K. T. (2012). Self-disclosure and student satisfaction with Facebook. Computers in Human Behavior, 28, 624-630. https://doi.org/10.1016/j.chb.2011.11.008

Spörrle, M., \& Bekk, M. (2014). Meta-analytic guidelines for evaluating single-item reliabilities of personality instruments. Assessment, 21, 272-285. https://doi.org/10.1177/1073191113498267 
Statista. (2018, October). Most famous social network sites worldwide as of October 2018, ranked by number of active users (in millions). Retrieved from https://www.statista.com/statistics/272014/global-social-networks-ranked-bynumber-of-users/

Strano, M. M. (2008). User descriptions and interpretations of self-presentation through Facebook profile images. Cyberpsychology: Journal of Psychosocial Research on Cyberspace, 2(2), article 5. Retrieved from https://cyberpsychology.eu/article/view/4212/3253

Taraszow, T., Aristodemou, E., Shitta, G., Laouris, Y., \& Arsoy, A. (2010). Disclosure of personal and contact information by young people in social networking sites: An analysis using Facebook profiles as an example. International Journal of Media \& Cultural Politics, 6, 81-101. https://doi.org/10.1386/macp.6.1.81/1

Tartaglia, S. (2016). Different modalities of using Facebook: The influence of actual social relations, wellbeing, and attitude towards the medium. Studia Psychologica, 58, 3-17. https://doi.org/10.21909/sp.2016.01.703

Teppers, E., Luyckx, K., Klimstra, T. A., \& Goossens, L. (2014). Loneliness and Facebook motives in adolescence: A longitudinal inquiry into directionality of effect. Journal of Adolescence, 37, 691-699.

https://doi.org/10.1016/j.adolescence.2013.11.003

Thelwall, M., Wilkinson, D., \& Uppal, S. (2010). Data mining emotion in social network communication: Gender differences in MySpace. Journal of the Association for Information Science and Technology, 61, 190-199.

https://doi.org/10.1002/asi.21180

van Deursen, A. J., Bolle, C. L., Hegner, S. M., \& Kommers, P. A. (2015). Modeling habitual and addictive smartphone behavior: The role of smartphone usage types, emotional intelligence, social stress, self-regulation, age, and gender. Computers in Human Behavior, 45, 411-420. https://doi.org/10.1016/j.chb.2014.12.039

Wee, J., Jang, S., Lee, J., \& Jang, W. (2017). The influence of depression and personality on social networking. Computers in Human Behavior, 74, 45-52. https://doi.org/10.1016/j.chb.2017.04.003

Williams, J. E., \& Best, D. L. (1990). Measuring sex stereotypes: A multination study. Newbury Park, CA: Sage.

Wohn, D. Y., \& Lee, Y. H. (2013). Players of Facebook games and how they play. Entertainment Computing, 4, 171178. https://doi.org/10.1016/j.entcom.2013.05.002

Wolniewicz, C. A., Tiamiyu, M. F., Weeks, J. W., \& Elhai, J. D. (2018). Problematic smartphone use and relations with negative affect, fear of missing out, and fear of negative and positive evaluation. Psychiatry Research, 262, 618-623. https://doi.org/10.1016/j.psychres.2017.09.058

Woods, S. A., \& Hampson, S. E. (2005). Measuring the Big Five with single items using a bipolar response scale. European Journal of Personality, 19(5), 373-390. https://doi.org/10.1002/per.542

Zywica, J., \& Danowski, J. (2008). The faces of Facebookers: Investigating social enhancement and social compensation hypotheses; predicting Facebook ${ }^{\mathrm{TM}}$ and offline popularity from sociability and self-esteem, and mapping the meanings of popularity with semantic networks. Journal of Computer-Mediated Communication, 14, 1-34. https://doi.org/10.1111/j.1083-6101.2008.01429.x 


\section{Correspondence to:}

Chiara Rollero

Department of Psychology, University of Turin

Via Verdi 10

10124 Torino - Italy

Phone number: +390116702534

Email: chiara.rollero(at)unito.it

Editorial record: First submission received on September 8, 2017. Revisions received on June 21, 2018, November 13, 2018, and December 21, 2018. Accepted for publication on January 2, 2019.

\section{About Authors}

Chiara Rollero, Ph.D., is Associate professor in Social Psychology at the Department of Psychology, University of Turin, Italy. Her research interests deal with mass media, gender issues, stereotypes, objectification processes, and violence.

Adriano Daniele, Bachelor's in Psychology, is currently a Master's student in Industrial-Organizational Psychology at Niccolò Cusano University in Rome, Italy.

Stefano Tartaglia, Ph.D., is Associate professor in Social Psychology at the Department of Psychology, University of Turin, Italy. His research interests pertain to the domain of social and community psychology. His recent works concern gender stereotyping, social influence of mass media, and the ethnic prejudice. 